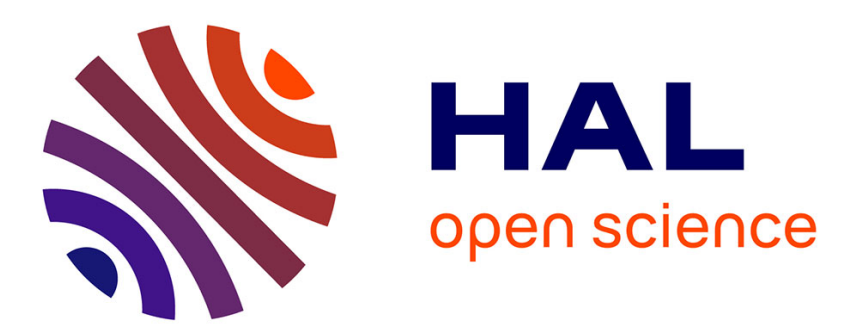

\title{
Photophysical properties of porphyrinic covalent cages endowed with different flexible linkers
}

\author{
Daniel Sánchez-Resa, Laëtitia Schoepff, Ryan Djemili, Stephanie Durot, \\ Valérie Heitz, Barbara Ventura
}

\section{- To cite this version:}

Daniel Sánchez-Resa, Laëtitia Schoepff, Ryan Djemili, Stephanie Durot, Valérie Heitz, et al.. Photophysical properties of porphyrinic covalent cages endowed with different flexible linkers. Journal of Porphyrins and Phthalocyanines, 2019, 23 (07n08), pp.841-849. 10.1142/S1088424619500925 . hal03415521

\author{
HAL Id: hal-03415521 \\ https://hal.science/hal-03415521
}

Submitted on 4 Nov 2021

HAL is a multi-disciplinary open access archive for the deposit and dissemination of scientific research documents, whether they are published or not. The documents may come from teaching and research institutions in France or abroad, or from public or private research centers.
L'archive ouverte pluridisciplinaire HAL, est destinée au dépôt et à la diffusion de documents scientifiques de niveau recherche, publiés ou non, émanant des établissements d'enseignement et de recherche français ou étrangers, des laboratoires publics ou privés. 


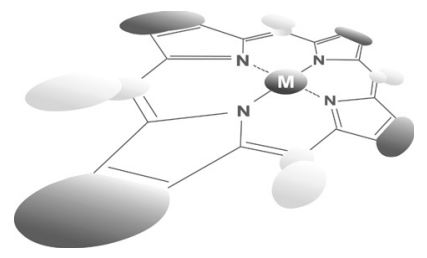

\title{
Photophysical properties of porphyrinic covalent cages endowed with different flexible linkers
}

\author{
Daniel Sánchez-Resa ${ }^{a}$, Laetitia Schoepff ${ }^{b}$, Ryan Djemili $^{b}$, Stéphanie Durot $^{\mathrm{b}}$, \\ Valérie Heitz ${ }^{* b}$ and Barbara Ventura*a \\ ${ }^{a}$ Istutito ISOF-CNR, Via P. Gobetti 101, 40129 Bologna, Italy \\ ${ }^{\mathrm{b}}$ Laboratoire de Synthèse des Assemblages Moléculaires Multifonctionnels, Institut de Chimie de Strasbourg, \\ CNRS/UMR 7177, Université de Strasbourg, 4, Rue Blaise Pascal, 67000 Strasbourg, France
}

This paper is part of the 2019 Women in Porphyrin Science special issue.

Dedicated to Dr. Lucia Flamigni, an excellent scientist and a mentor in the photophysics of porphyrin assemblies.

Received 31 May 2019

Accepted 12 July 2019

\begin{abstract}
In-depth photophysical studies of four flexible covalent cages bearing either two freebase porphyrins or one free-base porphyrin and one $\mathrm{Zn}$ (II) porphyrin, connected by linkers of different lengths, are reported. In the case of the cages with two free-base porphyrins, exciton coupling between the porphyrins is evidenced by large and split Soret bands in the absorption spectra, but the different length of the linkers has only a slight effect on their emission properties. Strong electronic interactions between the porphyrins are also evidenced for the cages that incorporate a free-base porphyrin and a $\mathrm{Zn}(\mathrm{II})$ porphyrin, with a more pronounced splitting of the Soret band for the system with longer linkers. In these cages, following excitation of the $\mathrm{Zn}$-porphyrin component, an almost quantitative energy transfer to the free-base unit occurs, with a rate 1.4 times faster in the cage with longer linkers $(1.4 \times$ $10^{11} \mathrm{~s}^{-1}$ vs. $\left.1.0 \times 10^{11} \mathrm{~s}^{-1}\right)$. This difference might reflect the more flattened conformation adopted by the cage equipped with longer and more flexible linkers, the latter allowing for a shorter interplanar distance between the porphyrins. The results are discussed in terms of classical and short-range energy transfer mechanisms.
\end{abstract}

KEYWORDS: porphyrins, molecular cages, photoinduced energy transfer.

\section{INTRODUCTION}

The design of functional systems based on molecular capsules has shown great potential in nanochemistry, since these systems can work as nanoreactors, molecular recognition systems or drug carriers, providing a confined environment that enhances molecular reactivity and catalysis [1-3].

Among the different possibilities in the design of molecular cages, the choice of metallated or freebase porphyrins leads to attractive architectures due to their chemical stability and their mimicry of natural

*Correspondence to: Valérie Heitz, tel.: 33 (0)3 688513 57, email: v.heitz@unistra.fr, Barbara Ventura, tel.: 0039051 6399817, email: barbara.ventura@isof.cnr.it. chromophores [1, 4-20]. Indeed, conversion of light energy into chemical energy performed in photosynthesis relies on efficient multistep energy transfer processes between natural chromophores belonging to the family of porphyrin derivatives (chlorophyll or bacteriochlorophyll molecules) organized in antennas that convey the energy towards the reaction center where the first electron transfer step towards a free-base porphyrin derivative occurs [21-27]. The efficiency of such processes is determined by the distance and mutual arrangement of these chromophores, and light-responsive cages have gained interest due to their ability to perform and control energy transfer processes $[6,7,18,28]$.

We have shown that bis-Zn(II) porphyrin cages equipped with four flexible linkers incorporating 
peripheral 1,2,3-triazole binding sites allow for a control of the distance and orientation between the two zinc(II) porphyrins. The cages adopt, in solution and in the solid state, a flattened conformation based on $\pi-\pi$ interactions between the porphyrins, whereas a large conformational change occurs upon binding in solution four $\mathrm{Ag}(\mathrm{I})$ ions to the peripheral ligands leading to open cages with two cofacial porphyrins separated by about $9 \AA$ [29-32]. Based on their tunable cavity size, these cages were evaluated as switchable receptors and their capacity to behave as allosteric receptors towards different kinds of guest molecules (a coordinating or a $\pi$-acceptor molecule) was demonstrated [31].

We here report bis-porphyrin cages constituted by either two free-base porphyrins or one zinc(II) porphyrin and one free-base porphyrin, connected by four flexible connectors that incorporate two 1,2,3-triazole ligands linked with either an ethyleneglycol unit or a diethyleneglycol unit. The latter units confer different lengths to the connectors, leading to different possible conformations of the systems. The four cages thus differ both in terms of porphyrin composition and lengths of the linkers. The study of the photophysical properties of these porphyrin cages is of importance regarding their potential as optical sensors of guest inclusion [33, 34]. Therefore, a detailed photophysical investigation has been performed by means of steady-state and timeresolved absorption and emission spectroscopy. The absorption and emission features of the cages and the photoinduced processes occurring within the porphyrin components are discussed in relation to the porphyrin nature and the structural difference between the systems.

\section{RESULTS AND DISCUSSION}

\section{Synthesis and characterization}

The synthesis of the cages incorporating two free-base or two zinc(II) porphyrins connected with short linkers [30] and with long linkers [29] have previously been reported as well as the model compounds $\mathbf{2 H}$-alkyne and Zn-alkyne [32] (Chart S1).
Both Zn(II)-monometallated cages, Zn-S-2H and Zn-L-2H, were prepared from cages incorporating two free-base porphyrins following a related procedure (Scheme 1). They were reacted with 1.1 equiv of $\mathrm{Zn}(\mathrm{OAc})_{2} \cdot 2 \mathrm{H}_{2} \mathrm{O}$ in a mixture of $\mathrm{CHCl}_{3} / \mathrm{MeOH}$ or $\mathrm{CH}_{2} \mathrm{Cl}_{2} / \mathrm{MeOH}[29,30]$. From the mixture of three cages (Zn(II)-monometallated cage, $\mathrm{Zn}$ (II) dimetallated cage and bis(free-base porphyrin) cage) thus obtained, the Zn(II)-monometallated cages $\mathbf{Z n - S - 2 H}$ and Zn-L-2H were isolated in $31 \%$ and $26 \%$ yield respectively, by preparative silica thin layer chromatography. They were characterized by 1D and 2D (COSY, NOESY) NMR experiments and mass spectrometry (see Figs S1-S13).

\section{Photophysical characterization}

Absorption and emission features of the four cages were characterized in DCM:MeOH (90:10). Model compounds $\mathbf{2 H}$-alkyne and $\mathbf{Z n}$-alkyne were also studied for comparison purposes.

Cages 2H-S-2H and $\mathbf{2 H}-\mathbf{L}-\mathbf{2 H}$, composed by two identical free-base porphyrins, show similar absorption spectra, with a Soret band which is slightly split and broadened compared with the sum of two spectra of the monomeric model 2H-alkyne (Fig. 1; see Fig. S14 for the spectrum of the model). These features can be ascribed to exciton coupling within the porphyrin units which are placed in close proximity in the cages, as previously observed and discussed for corresponding dimetallated $\mathrm{Zn}$ (II) cages [32]. The different lengths of the linkers slightly affects the absorption properties of the two cages. Indeed, the integrated molar absorption coefficients are almost identical for the two cages $\left(1.18 \times 10^{9} \mathrm{M}^{-1} \cdot \mathrm{cm}^{-2}\right.$ and $1.17 \times 10^{9} \mathrm{M}^{-1} \cdot \mathrm{cm}^{-2}$ for $\mathbf{2 H}-\mathbf{S}-\mathbf{2 H}$ and $\mathbf{2 H}-\mathbf{L}-\mathbf{2 H}$, respectively) and close to twice the absorption coefficient of the monomer $\mathbf{2 H}$-alkyne $\left(4.02 \times 10^{8} \mathrm{M}^{-1} \cdot \mathrm{cm}^{-2}\right)$.

The absorption spectra of the $\mathrm{Zn}$ (II)-monometallated cages $\mathbf{Z n - S - 2 H}$ and $\mathbf{Z n - L - 2 H}$ are shown in Fig. 2 and compared with the sum of the absorption spectra of models 2H-alkyne and Zn-alkyne. The Soret bands of the cages testify to inter-porphyrinic interactions, with a more pronounced exciton splitting in the cage with longer linkers, Zn-L-2H. The observed features 


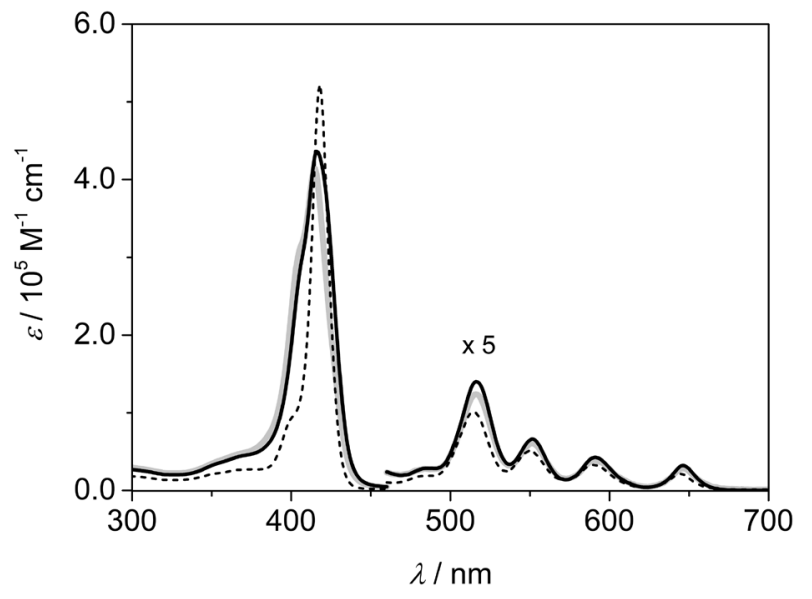

Fig. 1. Absorption spectra of $\mathbf{2 H - S}-\mathbf{2 H}$ (gray), 2H-L-2H (black full) and twice the absorption spectrum of $\mathbf{2 H}$-alkyne (black dashed) in DCM:MeOH (90:10). Absorption in the $460-700 \mathrm{~nm}$ region is amplified by a factor of five

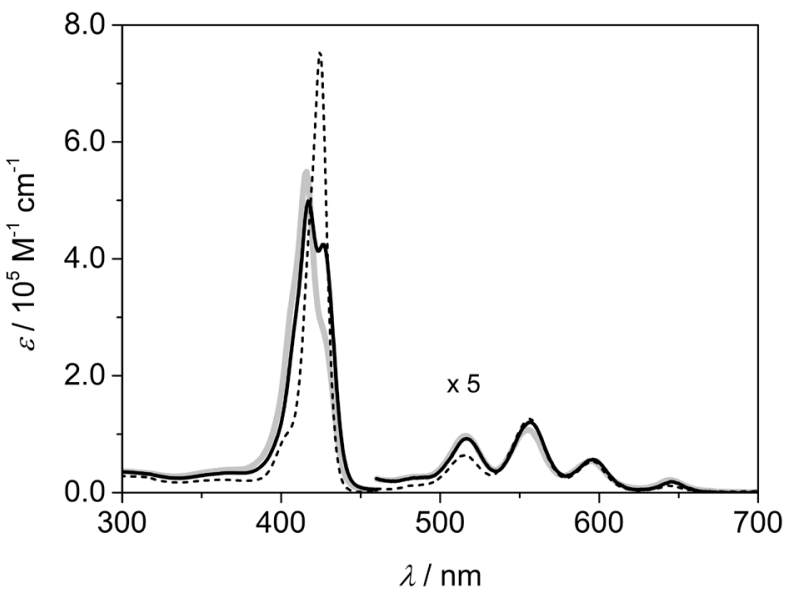

Fig. 2. Absorption spectra of $\mathbf{Z n - S - 2 H}$ (gray), Zn-L-2H (black full) and the sum of the absorption spectra of $\mathbf{2 H}$-alkyne and Zn-alkyne (black dashed) in DCM:MeOH (90:10). Absorption in the $460-700 \mathrm{~nm}$ region is amplified by a factor of five

are in accordance with a more slipped displacement of the porphyrins in $\mathbf{Z n}-\mathbf{L}-\mathbf{2 H}$ with respect to a cofacial disposition favored in the cage with shorter and more rigid linkers, Zn-S-2H, a structural description provided by theoretical modelling performed on our bis Zn-porphyrin cages analogs [32]. As a confirmation, integrated molar absorption coefficients of $1.32 \times 10^{9} \mathrm{M}^{-1} \cdot \mathrm{cm}^{-2}$ and $1.29 \times 10^{9} \mathrm{M}^{-1} \cdot \mathrm{cm}^{-2}$ are calculated for $\mathbf{Z n}-\mathbf{S}-\mathbf{2 H}$ and Zn-L-2H, respectively, values very close to the sum of the coefficients for $\mathbf{2 H}$-alkyne and $\mathbf{Z n}$-alkyne $(1.06 \times$ $10^{9} \mathrm{M}^{-1} \cdot \mathrm{cm}^{-2}$ ). To better take into account the coupling interactions, the spectra of the monometallated cages have been compared with the sum of half the spectra of the parent cages containing two identical porphyrins, i.e. the bis free-base $\mathbf{2 H}-\mathbf{S}-\mathbf{2 H}$ and $\mathbf{2 H}-\mathbf{L}-\mathbf{2 H}$ studied here and the two dimetallated Zn(II) cages $\mathbf{Z n - S - Z n ~ a n d ~} \mathbf{Z n - L - Z n ~}$ previously reported [32]. The comparison for $\mathbf{Z n - S - 2 H}$ and $\mathbf{Z n}-\mathbf{L}-\mathbf{2 H}$ with the sum of the respective free-base and $\mathrm{Zn}$ "half cages" is shown in Fig. S15. It is evident that in both cases the sum overlaps with a good approximation to the experimental spectrum of the monometallated cage, even in the Soret region which is more affected by interporphyrinic exciton coupling. It derives that the cages with two free-base or two Zn-porphyrins can be considered, from the photophysical point of view, as better models for the monometallated cages than the monomeric units 2H-alkyne and $\mathbf{Z n}$-alkyne, due to the strong interactions experienced by the porphyrins within these cages.

Luminescence determinations were performed both at room temperature in DCM:MeOH $(90: 10)$ and at $77 \mathrm{~K}$ in fregon DCM:MeOH (50:50) matrix. show similar emission features, with maxima at $c a$. $652 \mathrm{~nm}$ and $718 \mathrm{~nm}$, fluorescence quantum yields close to 0.080 and excited state lifetimes on the order of 9.0 ns (Fig. 3 and Table 1), indicating that the emission properties of the free-base porphyrin components are not affected by the conformation of the cages. On the other hand, selective excitation of the free-base unit at $630 \mathrm{~nm}$ in $\mathbf{Z n - S - 2 H}$ and $\mathbf{Z n - L - 2 H}$ (see Fig. S15) results in a lower quantum yield of 0.047 and 0.068 , respectively (Table 1), which is paralleled by a reduced lifetime of $6.7 \mathrm{~ns}$ and $7.6 \mathrm{~ns}$. This reveals a significant perturbation of the emission properties of the free-base component in the monometallated cages due to the presence of the Zn-porphyrin counterpart. A possible explanation is the close proximity of the $\mathrm{Zn}$ center of the metallated porphyrin to the core of the free-base partner, which can lead to a change in molecular symmetry or to an increased intersystem crossing rate [35-37] in the latter.

In order to confirm that the perturbation of the fluorescence features of the free-base porphyrin are due

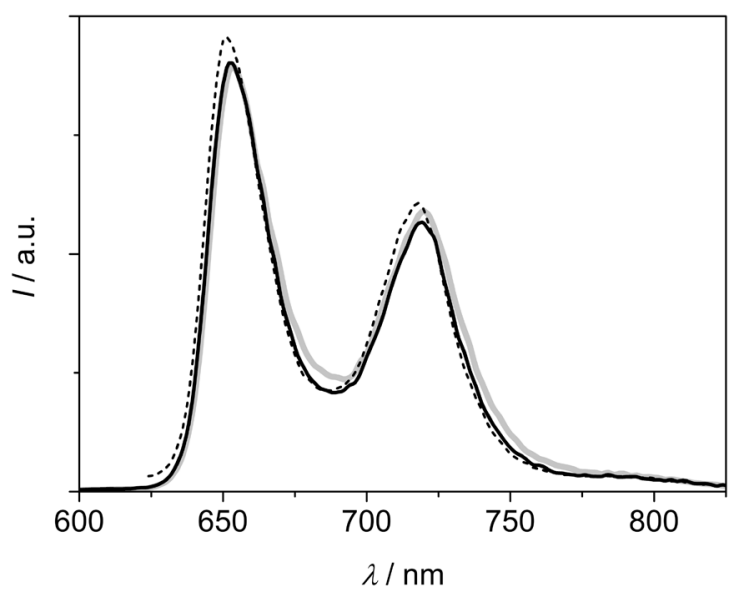

Fig. 3. Corrected emission spectra at room temperature of 2H-S-2H (gray), 2H-L-2H (black full) and 2H-alkyne (black dashed) in DCM:MeOH $(90: 10)$. The spectral areas are proportional to the emission quantum yields. $\lambda_{\mathrm{exc}}=550 \mathrm{~nm}$ 
Table 1. Luminescence data at room temperature and 77K, in DCM:MeOH (90:10) and (50:50), respectively

\begin{tabular}{|c|c|c|c|c|c|c|c|}
\hline & \multicolumn{4}{|c|}{$R T$} & \multicolumn{3}{|c|}{$77 \mathrm{~K}$} \\
\hline & & $\lambda_{\max } / \mathrm{nm}^{\mathrm{a}}$ & $\varphi_{\mathrm{ff}}{ }^{\mathrm{b}}$ & $\tau / \mathrm{ns}^{\mathrm{c}}$ & $\lambda_{\max } / \mathrm{nm}^{\mathrm{a}}$ & $\tau / \mathrm{ns}^{\mathrm{c}}$ & $E / \mathrm{eV}$ \\
\hline 2H-alkyne & ${ }^{1} \mathrm{H}_{2}$ & 652,718 & 0.083 & 8.5 & 648,716 & 11.4 & 1.91 \\
\hline \multirow[t]{2}{*}{ Zn-alkyne $^{f}$} & ${ }^{1} \mathrm{Zn}$ & 606,658 & 0.040 & 1.7 & 599,656 & 2.1 & 2.07 \\
\hline & ${ }^{3} \mathrm{Zn}$ & & & & 782 & $19.2 \times 10^{6}$ & 1.59 \\
\hline $2 \mathrm{H}-\mathrm{S}-2 \mathrm{H}$ & ${ }^{1} 2 \mathrm{H}-2 \mathrm{H}$ & 654,720 & 0.078 & 9.0 & 648,716 & 12.8 & 1.91 \\
\hline $2 \mathrm{H}-\mathrm{L}-2 \mathrm{H}$ & ${ }^{1} 2 \mathrm{H}-2 \mathrm{H}$ & 652,719 & 0.082 & 9.0 & 647,715 & 11.5 & 1.92 \\
\hline \multirow[t]{3}{*}{ Zn-S-2H } & $\mathrm{Zn}-{ }^{1} 2 \mathrm{H}$ & 652,717 & $0.047^{\mathrm{d}}$ & 6.7 & 645,713 & 11.5 & 1.92 \\
\hline & ${ }^{1} \mathrm{Zn}-2 \mathrm{H}$ & $606,-$ & - & $0.010^{\mathrm{e}}$ & $601,-$ & - & 2.06 \\
\hline & ${ }^{3} \mathrm{Zn}-2 \mathrm{H}$ & & & & 788 & $15.0 \times 10^{6}$ & 1.57 \\
\hline \multirow[t]{3}{*}{ Zn-L-2H } & $\mathrm{Zn}-{ }^{1} 2 \mathrm{H}$ & 652,718 & $0.068^{\mathrm{d}}$ & 7.6 & 644,712 & 11.2 & 1.93 \\
\hline & ${ }^{1} \mathrm{Zn}-2 \mathrm{H}$ & $608,-$ & - & $0.007^{\mathrm{e}}$ & $602,-$ & - & 2.06 \\
\hline & ${ }^{3} \mathrm{Zn}-2 \mathrm{H}$ & & & & 787 & $17.9 \times 10^{6}$ & 1.58 \\
\hline
\end{tabular}

to the close proximity of the $\mathrm{Zn}$-porphyrin component in the monometallated cages, an equimolar mixture of the models $\mathbf{2 H}$-alkyne and $\mathbf{Z n - a l k y n e ~ h a s ~ b e e n ~ a n a l y z e d . ~}$ Figure S16 reports absorption and emission spectra of the mixture, compared with the sum of the spectra of the single compounds. The emission spectrum of the mixture is in good agreement with the sum of the spectra of the models (Fig. S16b), indicating that there is no interaction between them in solution. ${ }^{\S}$ Moreover, a lifetime of $8.6 \mathrm{~ns}$ has been measured for the emission of $\mathbf{2} \mathbf{H}$-alkyne at $720 \mathrm{~nm}$ in the mixture, identical to that of the model alone (Table 1).

Upon excitation of both $\mathrm{Zn}$ - and free-base porphyrin components in the monometalled cages, the resulting luminescence is dominated by the bands of the freebase unit, while the Zn-porphyrin emission only appears as a weak band at $c a$. $608 \mathrm{~nm}$ (Table 1 and Fig. 4). To estimate the extent of the quenching of the Zn-porphyrin component in these cages, the emission of $\mathbf{Z n - S - 2 H}$ and Zn-L-2H has been compared to that of optically matched solutions of model cages with two free-base units or two $\mathrm{Zn}$-porphyrins, and the results are shown in Fig. 4. The excitation wavelengths were selected according to the absorption comparison previously described (Fig. S15), aiming at a substantial excitation of the Zn-porphyrin component in the monometallated cages (from $60 \%$ to $80 \%$ of the absorbed photons). By taking account the portion of excited Zn-porphyrin units anch cage in solution and comparing the intensity of the residual Zn-porphyrin emission at $608 \mathrm{~nm}$ with the intensity at the same wavelength for the bis $\mathrm{Zn}$-porphyrin model, it derives that the $\mathrm{Zn}$-porphyrins components are quenched over $90 \%$ in $\mathbf{Z n - S - 2 H}$ and $\mathbf{Z n - L}-\mathbf{2 H}$. This very efficient quenching can be safely ascribed to an energy transfer process to the free-base porphyrin counterpart. In fact, it is accompanied by a full recovery of the free-base porphyrin emission (Fig. 4): the bands at 652 and $718 \mathrm{~nm}$ recover for $c a .65 \%$ and $80 \%$ those of the bis free-base porphyrin model for $\mathbf{2 H - S - 2 H}$ and Zn-S-Zn, respectively, mirroring the ratios between the quantum yield of the free-base porphyrin unit in the monometallated cages and that of the same unit in the models (Table 1). A further confirmation of an almost complete $\mathrm{Zn} \rightarrow 2 \mathrm{H}$ energy transfer process comes from the good superimposition of excitation spectra, collected for both $\mathbf{Z n - S - 2 H}$ and Zn-L-2H at $720 \mathrm{~nm}$ where only the free-base porphyrin 


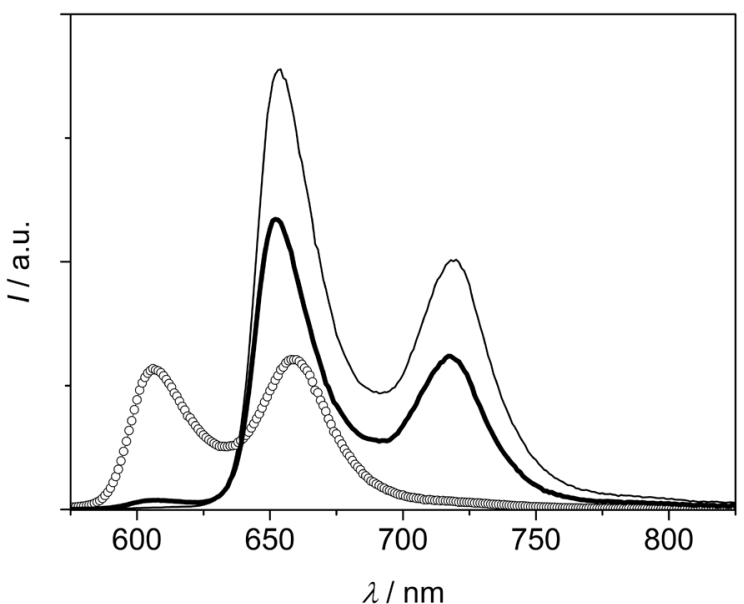

(a)

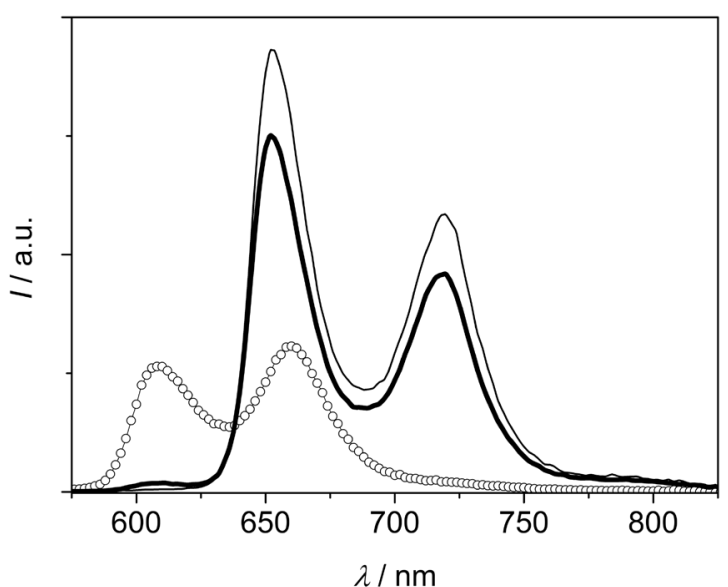

(b)

Fig. 4. Corrected emission spectra at room temperature of iso-absorbing solutions of (a) Zn-S-2H (black thick) and models 2H-S-2H (black thin) and Zn-S-Zn (dots), excitation at $557 \mathrm{~nm}$ (80\% of the photons absorbed by the Zn unit in Zn-S-2H), $A_{557}=$ 0.067; (b) Zn-L-2H (black thick) and models 2H-L-2H (black thin) and Zn-L-Zn (dots), excitation at $537 \mathrm{~nm}$ (60\% of the photons absorbed by the Zn unit in $\mathbf{Z n - L - 2 H}), A_{537}=0.046$; in DCM:MeOH (90:10)

unit emits, and absorption spectra (Fig. S17), indicating that whatever is the excited unit, the energy is conveyed to the lowest singlet excited state of the free-base porphyrin component.

As a verification that the observed energy transfer process is not occurring in freely diffusing porphyrin monomers, an equimolar mixture of models $2 \mathbf{H}$-alkyne and $\mathbf{Z n}$-alkyne, excited at $557 \mathrm{~nm}$, displays an emission spectrum perfectly matching with the sum of the spectra of the models (Fig. S18b), evidencing that there is no quenching of the Zn-porphyrin bands. Moreover, a fluorescence lifetime of $1.7 \mathrm{~ns}$ is measured for the mixture at $610 \mathrm{~nm}$, coincident with that of $\mathbf{Z n}$-alkyne (Table 1).

Emission measurements at $77 \mathrm{~K}$ in a DCM:MeOH (50:50) glassy mixture allowed definition of singlet excited state energy levels for all porphyrin components of the four cages and triplet excited state levels for the Zn-porphyrins in the monometallic cages, where phosphorescence was observed in gated mode. Luminescence spectra are shown in Figs S19 and S20 and the relevant data are summarized in Table 1. It can be noticed that, in the monometallated cages, the $\mathrm{Zn}$-porphyrin fluorescence is suppressed similarly to the room temperature case (Fig. S20), indicating that the quenching process occurring within these cages is very efficient even at low temperature.

In order to better characterize the photoinduced events, time-resolved luminescence experiments in the picosecond range were conducted for $\mathbf{Z n - S - 2 H}$ and Zn-L-2H. The measurements have been performed upon excitation at $560 \mathrm{~nm}$, where the $\mathrm{Zn}$-porphyrin component is prevalently excited, with a $100 \mathrm{fs}$ pulsed laser and acquiring luminescence images with a streak camera apparatus (time resolution: 1 ps). Low laser

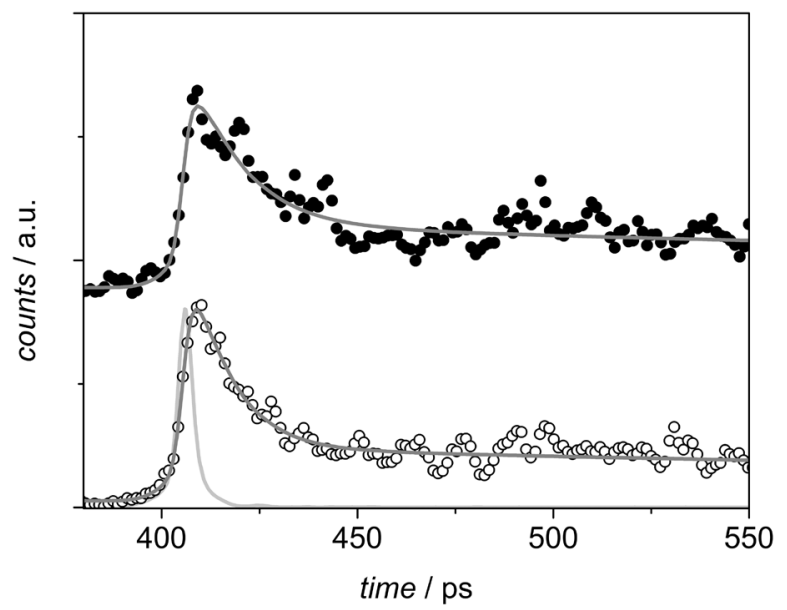

Fig 5. Normalized luminescence decays in the $600-620 \mathrm{~nm}$ spectral region for $\mathbf{Z n - S - 2 H}$ (full dots) and $\mathbf{Z n - L - 2 H}$ (open dots). The bi-exponential fittings are reported as grey lines. The excitation profile is shown in light grey. Excitation at $560 \mathrm{~nm}$ (26 $\mu \mathrm{J} /$ pulse)

power and fast image acquisition in analog integration mode were used (see the experimental section for details) to prevent photo-degradation of the compounds. The images identify the existence of a fast process, where a decay in the emission region of the Zn-porphyrin (600 $620 \mathrm{~nm}$ ) is accompanied by a rise in the $700-750 \mathrm{~nm}$ spectral region, where only emission from the free-base component is observable (Fig. 5 and Fig. S21). The decay of the Zn-porphyrin luminescence can be fitted with a bi-exponential function where the main component has a lifetime of $10 \mathrm{ps}$ in $\mathbf{Z n - S - 2 H}$ and 7 ps in $\mathbf{Z n - \mathbf { L } - 2 \mathbf { H }}$ (Fig. 5). The longer component (accounting for $c a .10 \%$ 
of the decay) can be attributed to a tail of the free-base porphyrin emission or a minor presence of a photoproduct. A precise fitting of the rise time of the free-base signal is difficult, but is compatible with the lifetime of the quenched Zn-porphyrin emission (Fig. S21), confirming the sensitization of the free-base singlet excited state upon energy transfer from the Zn-porphyrin component.

The difference between the quenched lifetimes of the $\mathrm{Zn}$-porphyrin component in the two cages is minimal but significant and indicates that the energy transfer process

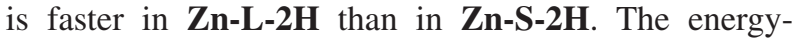
transfer rate, in fact, is $(1.0 \pm 0.1) \times 10^{11} \mathrm{~s}^{-1}$ and $(1.4 \pm$ $0.2) \times 10^{11} \mathrm{~s}^{-1}$ for $\mathbf{Z n - S - 2 H}$ and $\mathbf{Z n - L - 2 H}$, respectively (see the Experimental section for details). It derives that the process occurs with an efficiency close to $100 \%$ in both cages. To better analyze the nature of the energy transfer process, the data have been treated according to the Förster-type mechanism, which is usual between porphyrin chromophores. The overlap integral $\left(J^{\mathrm{F}}\right)$ between the emission spectrum of the donor (the bis Zn-porphyrin model) and the absorption spectrum of the acceptor (half the absorption spectrum of the bis freebase porphyrin cage) has been calculated to be $1.96 \times$ $10^{-14} \mathrm{~cm}^{3} \cdot \mathrm{M}^{-1}$ and $1.88 \times 10^{-14} \mathrm{~cm}^{3} \cdot \mathbf{M}^{-1}$ for $\mathbf{Z n - S - 2 H}$ and Zn-L-2H, respectively. An estimation of the geometrical factor $K^{2}$ (see the Experimental section) gives values of 0.09 for the cage with short linkers and 1.88 for the cage with long linkers (by considering $\theta_{\mathrm{D}}=\theta_{\mathrm{A}}=40^{\circ} \div 90^{\circ}$ in $\mathbf{Z n}-\mathbf{S}-2 \mathbf{H}$ and $\theta_{\mathrm{D}}=\theta_{\mathrm{A}}=15^{\circ} \div 40^{\circ}$ in $\mathbf{Z n}-\mathbf{L}-\mathbf{2 H}$ and $\phi$ varying from $0^{\circ}$ and $60^{\circ}$, according to the geometrical parameters derived for similar cages) [32]. With these parameters, and taking into account the fluorescence quantum yield and the lifetime of the donor in both cases, it is possible to evaluate the donor-acceptor distances that should result in the experimental rate constants on the basis of a Förster-type energy-transfer mechanism. The obtained distances are $6.6 \AA$ and $11.0 \AA$ for $\mathbf{Z n - S - 2 H}$ and $\mathbf{Z n - L - 2 H}$, respectively. While the first value is in good agreement with the distance between the two porphyrins estimated in the parent system $(7 \AA)$, the second value is not reasonable for a system where the long linkers allow a closer interaction between the porphyrins. Although the estimation of $K^{2}$ for these systems involves approximations, in the case of Zn-L-2H a possible deviation from the classical Förster treatment can be envisaged, with a weaker short-range dependence of the rate constant, as already observed for closely spaced $\pi$ systems [38]. At a supposed interplanar distance of $4 \AA$ estimated for the parent cage [32], we cannot also exclude a contribution from an electron exchange (Dexter) mechanism, that has been found to be operative at very short $(<5-6 \AA)$ donor-acceptor distances in cofacial porphyrinic systems [39, 40]. More detailed investigations on the nature of the energytransfer process are under way.

\section{EXPERIMENTAL}

\section{General}

All chemicals were of the best commercially available grade and used without further purification. $\mathrm{CH}_{2} \mathrm{Cl}_{2}$ and $\mathrm{CHCl}_{3}$ were distilled over $\mathrm{CaH}_{2}$ before use. Column chromatography was carried out using silica gel (Merck, silica gel 60, 63-200 or 40-63 $\mu \mathrm{m}$ ). Mass spectra were obtained by using a Bruker MicroTOF spectrometer in electrospray mode (ES-MS). Nuclear Magnetic Resonance (NMR) spectra for ${ }^{1} \mathrm{H}$ and ${ }^{13} \mathrm{C}$ were acquired on Bruker AVANCE 300, 400, 500 spectrometers. The ${ }^{1} \mathrm{H}$ and ${ }^{13} \mathrm{C}$ spectra were referenced to residual solvent peaks. $\left(\mathrm{CDCl}_{3}, 7.24\right.$ and 77.16; $\mathrm{CD}_{2} \mathrm{Cl}_{2}, 5.32$ and 53.84; DMSO, 2.50 and 39.52; DMF, 8.03 and 163.15).

\section{Synthesis}

Synthesis of monometallated cage Zn-S-2H. Zinc acetate $\mathrm{Zn}(\mathrm{OAc})_{2} .2 \mathrm{H}_{2} \mathrm{O}$ (5.4 mg, $24.8 \mu \mathrm{mol}, 1.1$ equiv.) was added to a stirred solution of cage $2 \boldsymbol{H}-\boldsymbol{S}-\mathbf{2 H}$ (50.0 mg, 22.5 umol, 1 equiv.) in $25 \mathrm{~mL} \mathrm{CHCl}_{3} /$ $\mathrm{MeOH}(9: 1 \mathrm{v} / \mathrm{v})$ at room temperature. Completion was checked by thin layer chromatography $\left(\mathrm{SiO}_{2}, \mathrm{CH}_{2} \mathrm{Cl}_{2} /\right.$ $\left.\mathrm{CHCl}_{3} / \mathrm{MeOH} 5 / 5 / 1\right)$. After three hours, the solvent was evaporated and the residue was purified by two consecutive preparative thin layer chromatographies eluted with $\mathrm{CH}_{2} \mathrm{Cl}_{2} / \mathrm{CHCl}_{3} / \mathrm{MeOH} 45 / 45 / 10$ and flash chromatography using $\left.\mathrm{CH}_{2} \mathrm{Cl}_{2} / \mathrm{MeOH} 95 / 5\right)$ to afford a purple solid (16 mg, $31 \%$ yield). ${ }^{1} \mathbf{H}$ NMR (500 MHz, DMF-d $\left._{7}\right): \delta(\mathrm{ppm})=8.49\left(8 \mathrm{H}\right.$, br s, $\left.\mathrm{H}_{\mathrm{pyr}}{ }^{\prime}\right), 8.42(8 \mathrm{H}$, $\left.\mathrm{s}, \mathrm{H}_{\mathrm{pyr}}\right), 8.37\left(8 \mathrm{H}, \mathrm{s}, \mathrm{H}_{\mathrm{t}}, \mathrm{H}_{\mathrm{t}^{\prime}}\right), 8.12\left(4 \mathrm{H}, \mathrm{d},{ }^{3} \mathrm{~J}=7.6 \mathrm{~Hz}\right.$, $\left.\mathrm{H}_{\mathrm{o}^{\prime} \text { out }}\right), 8.08\left(4 \mathrm{H}, \mathrm{d},{ }^{3} \mathrm{~J}=7.6 \mathrm{~Hz}, \mathrm{H}_{\mathrm{o} \text { out }}\right), 7.79\left(4 \mathrm{H}, \mathrm{d},{ }^{3} \mathrm{~J}=\right.$ $\left.7.6 \mathrm{~Hz}, \mathrm{H}_{\mathrm{m}^{\prime} \text { out }}\right), 7.74\left(4 \mathrm{H}, \mathrm{d},{ }^{3} \mathrm{~J}=7.6 \mathrm{~Hz}, \mathrm{H}_{\mathrm{m}^{\prime} \text { out }}\right), 7.14$ $\left(4 \mathrm{H}, \mathrm{d},{ }^{3} \mathrm{~J}=7.6 \mathrm{~Hz}, \mathrm{H}_{\mathrm{o}}\right.$ ' in $), 7.09\left(4 \mathrm{H}, \mathrm{d},{ }^{3} \mathrm{~J}=7.6 \mathrm{~Hz}, \mathrm{H}_{\mathrm{o} \text { in }}\right)$, $6.72\left(8 \mathrm{H}, \mathrm{m},{ }^{3} \mathrm{~J}=7.6 \mathrm{~Hz}, \mathrm{H}_{\mathrm{min}}, \mathrm{H}_{\mathrm{m}^{\prime} \text { in }}\right), 5.84\left(8 \mathrm{H}, \mathrm{s}, \mathrm{H}_{1}\right)$, $5.81\left(8 \mathrm{H}, \mathrm{s}, \mathrm{H}_{1}\right), 4.70\left(16 \mathrm{H}, \mathrm{s}, \mathrm{H}_{2}, \mathrm{H}_{2^{\prime}}\right), 3.76(16 \mathrm{H}, \mathrm{m}$, $\left.\mathrm{H}_{3}\right),-3.19(2 \mathrm{H}, \mathrm{s}, \mathrm{NH}) .{ }^{13} \mathrm{C}$ NMR $\left(126 \mathrm{MHz}, \mathrm{DMF}-\mathrm{d}_{7}\right)$ : $\delta(\mathrm{ppm})=150.5\left(\mathrm{C}_{2}\right), 146.2\left(\mathrm{C}_{10+10^{\prime}}\right), 143.6\left(\mathrm{C}_{4}\right), 142.0$ $\left(\mathrm{C}_{4^{\prime}}\right), 137.0\left(\mathrm{C}_{5^{\prime} \text { out }}\right), 136.3\left(\mathrm{C}_{5 \text { out }}\right), 135.7-135.4 \mathrm{C}_{7}+$ $\left.\mathrm{C}_{7^{\prime}}+\mathrm{C}_{5^{\prime} \text { in }+5 \text { in }}\right), 132.4\left(\mathrm{C}_{1}\right), 127.5\left(\mathrm{C}_{6^{\prime} \text { out }}\right), 127.2\left(\mathrm{C}_{6 \text { out }}\right)$, $126.7\left(\mathrm{C}_{6^{\prime}}\right.$ in $), 126.3\left(\mathrm{C}_{6 \text { in }}\right), 125.4\left(\mathrm{C}_{9^{\prime}}\right), 125.3\left(\mathrm{C}_{9}\right), 120.8$ $\left(\mathrm{C}_{3}\right), 120.6\left(\mathrm{C}_{3^{\prime}}\right), 70.6\left(\mathrm{C}_{12}\right), 65.3\left(\mathrm{C}_{11^{\prime}+11}\right), 53.9\left(\mathrm{C}_{8^{\prime}+8}\right)$; pyrrolic ${ }^{13} \mathrm{C} \mathrm{C}_{1^{\prime}}$, and $\mathrm{C}_{2}$, are too enlarged to be observed at 298K. ES-MS: $\mathrm{m} / \mathrm{z}(\%)$ calcd for $\left[\mathrm{C}_{128} \mathrm{H}_{108} \mathrm{~N}_{32} \mathrm{O}_{8} \mathrm{Zn}\right]^{2+} / 2$ : 1142.4154; found : 1142.4172 (100) $\left[\mathrm{M}+2 \mathrm{H}^{+}\right] / 2$.

Synthesis of monometallated cage $\mathrm{Zn}-\mathbf{L}-2 \mathrm{H}$. Zinc acetate $\mathrm{Zn}(\mathrm{OAc})_{2} \cdot 2 \mathrm{H}_{2} \mathrm{O}(9.85 \mathrm{mg}, 44.9 \mu \mathrm{mol}, 1.1$ equiv. $)$ was added to a stirred solution of cage $\mathbf{2 H}-\mathbf{L}-\mathbf{2} \boldsymbol{H}$ (97.8 mg, $40.8 \mu \mathrm{mol}, 1$ equiv.) in $\mathrm{CH}_{2} \mathrm{Cl}_{2} / \mathrm{MeOH}(9: 1 \mathrm{v} / \mathrm{v}$ ) and refluxed overnight. The solvents were evaporated and the residue was purified by preparative thin layer chromatography eluted with $\mathrm{CH}_{2} \mathrm{Cl}_{2} / \mathrm{CHCl}_{3} / \mathrm{MeOH}$ $44 / 50 / 10$ to afford a purple solid $(26.1 \mathrm{mg}, 26 \%$ yield). ${ }^{1}$ H NMR $\left(500 \mathrm{MHz}\right.$, DMF-d $\left.\mathrm{d}_{7}\right): \delta(\mathrm{ppm})=8.52(8 \mathrm{H}, \mathrm{br}$ 
$\left.\mathrm{s}, \mathrm{H}_{\mathrm{pyr}}{ }^{\prime}\right), 8.44\left(8 \mathrm{H}, \mathrm{s}, \mathrm{H}_{\mathrm{pyr}}\right), 8.29\left(4 \mathrm{H}, \mathrm{s}, \mathrm{H}_{\mathrm{t}}\right), 8.25(4 \mathrm{H}$, $\left.\mathrm{s}, \mathrm{H}_{\mathrm{t}^{\prime}}\right), 8.14\left(4 \mathrm{H}, \mathrm{d},{ }^{3} \mathrm{~J}=7.6 \mathrm{~Hz}, \mathrm{H}_{\mathrm{o}^{\prime} \text { out }}\right), 8.09$ (4 H, d, $\left.{ }^{3} \mathrm{~J}=7.6 \mathrm{~Hz}, \mathrm{H}_{\mathrm{o} \text { out }}\right), 7.71\left(4 \mathrm{H}, \mathrm{d},{ }^{3} \mathrm{~J}=7.6 \mathrm{~Hz}, \mathrm{H}_{\mathrm{m}^{\prime} \text { out }}\right), 7.66$ $\left(4 \mathrm{H}, \mathrm{d},{ }^{3} \mathrm{~J}=7.6 \mathrm{~Hz}, \mathrm{H}_{\mathrm{m} \text { out }}\right), 7.22\left(4 \mathrm{H}, \mathrm{d},{ }^{3} \mathrm{~J}=7.6 \mathrm{~Hz}\right.$, $\left.\mathrm{H}_{\mathrm{o}^{\prime} \text { in }}\right), 7.17\left(4 \mathrm{H}, \mathrm{d},{ }^{3} \mathrm{~J}=7.6 \mathrm{~Hz}, \mathrm{H}_{\mathrm{o}}\right), 6.55\left(4 \mathrm{H}, \mathrm{d},{ }^{3} \mathrm{~J}=\right.$ $\left.7.6 \mathrm{~Hz}, \mathrm{H}_{\mathrm{m}^{\prime} \text { in }}\right), 6.52\left(4 \mathrm{H}, \mathrm{d},{ }^{3} \mathrm{~J}=7.6 \mathrm{~Hz}, \mathrm{H}_{\mathrm{m} \text { in }}\right), 5.71$ $\left(8 \mathrm{H}, \mathrm{s}, \mathrm{H}_{1^{\prime}}\right), 5.67\left(8 \mathrm{H}, \mathrm{s}, \mathrm{H}_{1}\right), 4.66\left(8 \mathrm{H}, \mathrm{s}, \mathrm{H}_{2^{\prime}}\right), 4.65$ $\left(8 \mathrm{H}, \mathrm{s}, \mathrm{H}_{2}\right), 3.71\left(16 \mathrm{H}, \mathrm{m}, \mathrm{H}_{3}\right), 3.66\left(16 \mathrm{H}, \mathrm{m}, \mathrm{H}_{4}\right),-2.87$ $(2 \mathrm{H}, \mathrm{s}, \mathrm{NH}) .{ }^{13} \mathrm{C}$ NMR $\left(126 \mathrm{MHz}, \mathrm{DMF}_{-} \mathrm{d}_{7}\right): \delta(\mathrm{ppm})=$ $150.7\left(\mathrm{C}_{2}\right), 146.1\left(\mathrm{C}_{10+10^{\prime}}\right), 143.6\left(\mathrm{C}_{4}\right), 142.1\left(\mathrm{C}_{4^{\prime}}\right), 136.9$ $\left(\mathrm{C}_{5^{\prime} \text { out }}\right), 136.2\left(\mathrm{C}_{5 \text { out }}\right), 135.7\left(\mathrm{C}_{7^{\prime}}\right), 134.6\left(\mathrm{C}_{7}+\mathrm{C}_{5^{\prime} \text { in }+5 \text { in }}\right)$, $132.5\left(\mathrm{C}_{1}\right), 127.5\left(\mathrm{C}_{6^{\prime} \text { out }}\right), 127.1\left(\mathrm{C}_{6 \text { out }}\right), 126.8\left(\mathrm{C}_{6^{\prime} \text { in }}\right), 126.3$ $\left(\mathrm{C}_{6 \text { in }}\right), 125.3\left(\mathrm{C}_{9^{\prime}}\right), 125.3\left(\mathrm{C}_{9}\right), 121.1\left(\mathrm{C}_{3}\right), 120.8\left(\mathrm{C}_{3^{\prime}}\right)$, $71.4\left(\mathrm{C}_{12}\right), 70.7\left(\mathrm{C}_{13}\right), 65.2\left(\mathrm{C}_{11^{\prime}+11}\right), 53.8\left(\mathrm{C}_{8^{\prime}+8}\right)$; pyrrolic ${ }^{13} \mathrm{C} \mathrm{C}_{1^{\prime}}$ and $\mathrm{C}_{2}$, are too enlarged to be observed at $298 \mathrm{~K}$. ES-MS: $\mathrm{m} / \mathrm{z}(\%)$ calcd for $\left[\mathrm{C}_{136} \mathrm{H}_{122} \mathrm{~N}_{32} \mathrm{O}_{12} \mathrm{ZnNa}_{2}\right]^{2+} / 2$ : 1252.4498; found : 1252.4521 (100) $\left[\mathrm{M}+2 \mathrm{Na}^{+}\right] / 2$; calcd for $\left[\mathrm{C}_{136} \mathrm{H}_{122} \mathrm{~N}_{32} \mathrm{O}_{12} \mathrm{ZnNa}\right]^{+}$: 2481.9104 ; found : 2482.9233 (20).

\section{Absorption and emission spectroscopy, photophysics}

Spectroscopic grade DCM and $\mathrm{MeOH}$ were from Merck and used as received. Silver trifluoromethanesulfonate $(\mathrm{Ag}(\mathrm{OTf}))$ was from Sigma-Aldrich and was stored under argon in a sealed vial in dark and dry conditions. $\mathrm{Ag}$ (OTf) solutions were used fresh and kept in the dark during the measurements.

Absorption Spectra were recorded with Perkin-Elmer Lambda 650 UV-vis and Perkin-Elmer Lambda 950 UV-VIS-NIR spectrophotometers. Integrated absorption coefficients were calculated by plotting molar absorption coefficients as a function of absorption energy (in wavenumbers) and calculating the area under the curves.

Emission spectra were collected with an Edinburgh FLS920 fluorimeter, equipped with a Peltier-cooled Hamamatsu R928 PMT (200-850 nm), and corrected for the wavelength-dependent phototube response. Corrected excitation spectra were recorded with the same fluorimeter. Emission quantum yields were evaluated from the area of the luminescence spectra, corrected for the photomultiplier response, with reference to mesotetraphenylporphyrin inaerated toluene $\left(\varphi_{\mathrm{fl}}=0.11\right)$ [41] Measurements at $77 \mathrm{~K}$ were performed with the same fluorimeter, making use of Pyrex tubes dipped in liquid nitrogen in a quartz Dewar. Gated emission spectra were acquired by using a time-gated spectral scanning mode and a $\mu \mathrm{F} 920 \mathrm{H}$ Xenon flash lamp (pulse width $<2 \mu \mathrm{s}$, repetition rate between 0.1 and $100 \mathrm{~Hz}$ ) as excitation source. Spectra were corrected for the wavelengthdependent photomultiplier response. Triplet excited state lifetimes were measured with the same apparatus in the multichannel scaling mode.

Fluorescence lifetimes in the nanosecond range were detected by using an IBH Time Correlated Single
Photon Counting apparatus with Nano-LED excitation at $465 \mathrm{~nm}$. Analysis of the decay profiles against time was performed using the Decay Analysis Software DAS6 provided by the manufacturer.

Fluorescence lifetimes in the ps regime were measured by means of a Hamamatsu synchroscan streak-camera apparatus (C10910-05 main unit and M10911-01 synchroscan unit) equipped with an ORCA-Flash 4.0 V2 charge-coupled device (CCD) and an Acton spectrograph SP2358. As excitation source, a Newport Spectra Physics Solstice-F-1K-230 V laser system, combined with a TOPAS Prime (TPR-TOPAS-F) optical parametric amplifier (pulse width: $100 \mathrm{fs}, 1 \mathrm{kHz}$ repetition rate) [42] was used, tuned at $560 \mathrm{~nm}$. To reduce photo-degradation, the pump energy on the sample was reduced to $26 \mu \mathrm{J} /$ pulse. Emission from the sample, collected at a right angle with a $1 \mathrm{~mm}$ slit, was focused by means of a system of lenses into the spectrograph slit. Streak images were taken in analog integration mode (100 exposures, exposure time: $2 \mathrm{~s}$ ). The decays were measured over emission spectral ranges of 20-40 nm. HPD-TA 9.3 software from Hamamatsu was used for data acquisition and analysis. The overall time resolution of the system after deconvolution procedure was $1 \mathrm{ps}$.

The energy transfer rate in the monometallic cages is calculated as $k_{\mathrm{en}}=1 / \tau-1 / \tau_{0}$, in which $\tau$ is the lifetime of the quenched donor unit and $\tau_{0}$ the lifetime of the unquenched unit, i.e. the lifetime of the reference model (the $\mathrm{Zn}$-component in the bis $\mathrm{Zn}$-porphyrin cages): $1.7 \mathrm{~ns}$ for $\mathbf{Z n - S - Z n}$ and $1.6 \mathrm{~ns}$ for $\mathbf{Z n - L - Z n ~ [ 3 2 ] . ~}$ The error for the energy transfer rate value has been estimated according to the partial derivative methods and by taking the temporal resolution of the measuring system as uncertainty on the lifetime value ( 1 ps for $\tau$, measured with the streak camera apparatus, and $0.2 \mathrm{~ns}$ for $\tau_{0}$, measured with the Time Correlated Single Photon Counting equipment). The energy transfer efficiency is defined as $\eta_{\text {en }}=k_{\text {et }}\left(k_{\text {et }}+\tau_{0}^{-1}\right)$.

The calculation of the energy-transfer rate constant according to the Förster theory was performed by using equation (1) [43], where $d_{D A}$ is the distance between the centers of mass of the donor and acceptor, $\Phi$ and $\tau$ are the emission quantum yield and lifetime of the donor, $J^{F}$ the overlap integral, $n$ the refractive index of the solvent and $K^{2}$ the orientation factor, calculated according to equation (2) [44], where $\theta_{\mathrm{D}}$ and $\theta_{\mathrm{A}}$ are the angles formed between the line connecting the donor and acceptor centers and the transition moments of the donor and acceptor, respectively, and $\phi$ is the angle between the projections of the transition moments on a plane perpendicular to the line connecting the centers of the donor and the acceptor.

$$
\begin{gathered}
k_{e n}^{F}=\frac{8.8 \times 10^{-25} k^{2} \Phi}{n^{4} \tau d_{D A}^{6}} J^{F} \\
K^{2}=\left(\sin \theta_{\mathrm{D}} \sin \theta_{\mathrm{A}} \cos \phi-2 \cos \theta_{\mathrm{D}} \cos \theta_{\mathrm{A}}\right)^{2}
\end{gathered}
$$


Estimated errors are $10 \%$ on lifetimes, $20 \%$ on quantum yields, $20 \%$ on molar absorption coefficients and $3 \mathrm{~nm}$ on emission and absorption peaks.

\section{CONCLUSION}

The photophysics of flexible covalent cages bearing either two free-base porphyrins or one free-base porphyrin and one $\mathrm{Zn}$ (II) porphyrin, connected by flexible linkers of different lengths, has been investigated in detail by means of steady-state and time-resolved spectroscopic studies. Strong exciton interactions between the porphyrins have been evidenced in all cases, due to the close proximity of these units in the collapsed structure of the cages. The emission features of the porphyrins depend on the composition of the cage and/or on the lengths of the linkers: the free-base units display altered fluorescence quantum yield and lifetime only in the monometallated cages, where the $\mathrm{Zn}$ counterpart influences their radiative behavior, with a more important reduction in the cage with shorter linkers. The $\mathrm{Zn}$-porphyrins are quantitatively quenched by a fast energy transfer process that sensitizes the free-base emission in both monometallated cages. This photoinduced process is slightly faster in the cage with longer linkers, probably due to the very short interplanar distance between the porphyrins in this cage, supposed to be around $4 \AA$. The results highlight the role of the linkers and of the arrangement of the components in the photophysics of flexible porphyrinic cages.

\section{Acknowledgments}

The International Center for Frontier Research in Chemistry, icFRC (www.icfrc.fr), and the LabEx-CSC are gratefully acknowledged for a Ph.D. fellowship to L.S. The Ministry of Education and Research is acknowledged for a Ph.D. fellowship to R.D. We also thank the ANR Agency for the funding of the project ANR 14-CE06-0010 "Switchable cages" and the Italian CNR (Project "PHEEL"). Prof. Isabella Daidone, Dr. Laura Zanetti-Polzi (University of L'Aquila) and Dr. Andrea Barbieri (ISOF-CNR) are thanked for helpful discussion. EC is acknowledged for the NOAH project, grant N. 765297 under H2020-MSCA-ITN-2017.

\section{Notes}

$\S$ The emission contribution from the model Zn-alkyne in the mixture upon excitation at $630 \mathrm{~nm}$ is not negligible at the concentration used, which is optimized for the freebase porphyrin excitation.

\section{REFERENCES}

1. Durot S, Taesch J and Heitz V. Chem. Rev. 2014; 114: 8542-8578.

2. Chakrabarty R, Mukherjee PS and Stang PJ. Chem. Rev. 2011; 111: 6810-6918.
3. Mukhopadhyay RD, Kim Y, Koo J and Kim K. Acc. Chem. Res. 2018; 51: 2730-2738.

4. Balaban TS. Acc. Chem. Res. 2005; 38: 612-623.

5. Li W-S, Kim KS, Jiang D-L, Tanaka H, Kawai T, Kwon JH, Kim D and Aida T. J. Am. Chem. Soc. 2006; 128: 10527-10532.

6. Harvey PD, Stern C, Gros CP and Guilard R. Coord. Chem. Rev. 2007; 251: 401-428.

7. Nakamura Y, Aratani N and Osuka A. Chem. Soc. Rev. 2007; 36: 831-845.

8. Satake A and Kobuke Y. Org. Biomol. Chem. 2007; 5: 1679-1691.

9. Gust D, Moore TA and Moore AL. Acc. Chem. Res. 2009; 42: 1890-1898.

10. Wasielewski MR. Acc. Chem. Res. 2009; 42: 1910-1921.

11. Lindsey JS and Bocian DF. Acc. Chem. Res. 2011; 44: 638-650.

12. Pellegrin Y and Odobel F. Coord. Chem. Rev. 2011; 255: 2578-2593.

13. Sprafke JK, Kondratuk DV, Wykes M, Thompson AL, Hoffmann M, Drevinskas R, Chen W-H, Yong CK, Kärnbratt J, Bullock JE, Malfois M, Wasielewski MR, Albinsson B, Herz LM, Zigmantas D, Beljonne D and Anderson HL. J. Am. Chem. Soc. 2011; 133: 17262-17273.

14. Griffith MJ, Sunahara K, Wagner P, Wagner K, Wallace GG, Officer DL, Furube A, Katoh R, Mori S and Mozer AJ. Chem. Commun. 2012; 48: 4145-4162.

15. Wytko JA, Ruppert R, Jeandon C and Weiss J. Chem. Commun. 2018; 54: 1550-1558.

16. Hong S, Rohman MdR, Jia J, Kim Y, Moon D, Kim Y, Ko YH, Lee E and Kim K. Angew. Chem. 2015; 127: 13439-13442.

17. Yu C, Long H, Jin Y and Zhang W. Org. Lett. 2016; 18: 2946-2949.

18. Hwang I-W, Kamada T, Ahn TK, Ko DM, Nakamura T, Tsuda A, Osuka A and Kim D. J. Am. Chem. Soc. 2004; 126: 16187-16198.

19. Hernández-Eguía LP, Escudero-Adán EC, Pintre IC, Ventura B, Flamigni L and Ballester P. Chem. Eur. J. 2011; 17: 14564-14577.

20. Durot S, Flamigni L, Taesch J, Dang TT, Heitz V and Ventura B. Chem. - Eur. J. 2014; 20: 9979-9990.

21. Huber R. Angew. Chem., Int. Ed. Engl. 1989; 28: 848-869.

22. Deisenhofer J and Michel H. Angew. Chem., Int. Ed. Engl. 1989; 28: 829-847.

23. Deisenhofer J, Epp O, Sinning I and Michel $\mathrm{H}$. J. Mol. Biol. 1995; 246: 429-457.

24. Papiz MZ, Prince SM, Howard T, Cogdell RJ and Isaacs NW. J. Mol. Biol. 2003; 326: 1523-1538.

25. Roszak AW. Science 2003; 302: 1969-1972.

26. Umena Y, Kawakami K, Shen J-R and Kamiya N. Nature 2011; 473: 55-60.

27. Pšenčík J and Tuma R. In The Structural Basis of Biological Energy Generation, Vol 39, M.F. 
Hohmann-Marriot (ed.) Springer Science+Business Media Dodrecht, 2014; pp 77-109.

28. Flamigni L, Ventura B, Oliva AI and Ballester P. Chem. - Eur. J. 2008; 14: 4214-4224.

29. Kocher L, Durot S and Heitz V. Chem. Commun. 2015; 51: 13181-13184.

30. Schoepff L, Kocher L, Durot S and Heitz V. J. Org. Chem. 2017; 82: 5845-5851.

31. Djemili R, Kocher L, Durot S, Peuroren A, Rissanen K and Heitz V. Chem. - Eur. J. 2018; 25: 1 - 8.

32. Zanetti-Polzi L, Amadei A, Djemili R, Durot S, Schoepff L, Heitz V, Ventura B and Daidone I. J. Phys. Chem. C 2019; 123: 13094-13103.

33. Ishihara S, Labuta J, Van Rossom W, Ishikawa D, Minami K, Hill JP and Ariga K. Phys. Chem. Chem. Phys. 2014; 16: 9713-9746.

34. Ding Y, Zhu W-H and Xie Y. Chem. Rev. 2017; 117: 2203-2256.

35. Fransson T, Saue T and Norman P. J. Chem. Theory Comput. 2016; 12: 2324-2334.

36. Minaev B and Ågren H. Chem. Phys. 2005; 315: 215-239.
37. Horiuchi H, Terashima K, Sakai A, Suda D, Yoshihara T, Kobayashi A, Tobita S and Okutsu T. J. Photochem. Photobiol. Chem. 2016; 321: 72-78.

38. Wong KF, Bagchi B and Rossky PJ. J. Phys. Chem. A 2004; 108: 5752-5763.

39. Faure S, Stern C, Guilard R and Harvey PD. J. Am. Chem. Soc. 2004; 126: 1253-1261.

40. Cho HS, Jeong DH, Yoon M-C, Kim YH, Kim Y-R, Kim D, Jeoung SC, Kim SK, Aratani N, Shinmori H and Osuka A. J. Phys. Chem. A 2001; 105: 4200-4210

41. Seybold PG and Gouterman M. J. Mol. Spectrosc. 1969; 31: 1-13.

42. Briš A, Trošelj P, Margetić D, Flamigni L and Ventura B. ChemPlusChem 2016; 81: 985-994.

43. Förster Th. Discuss. Faraday Soc. 1959; 27: 7-17.

44. Van Der Meer BW. Coker III G and Simon S-Y Chen. In Resonance Energy Transfer: Theory and Data, Wiley VCH Weinheim, 1994; pp. 55-83. 